\title{
Rethinking the Way Out for College English Teaching-After China's Reform in National College Entrance Exam in English
}

\author{
Liu Peng \\ School of Foreign Languages, Sichuan University of Science and Technology, Zigong, China \\ Xianjun Tan \\ School of Foreign Languages, Sichuan University of Science and Technology, Zigong, China \\ Fang Xie \\ School of Foreign Languages, Sichuan University of Science and Technology, Zigong, China
}

\begin{abstract}
In the past thirty years, English shares the equal position with Chinese and Math in China's national college entrance exam (also gaokao). To help test takes achieve higher scores in the once-in-a-lifetime test, students (kids) start to contact English soon after they step into schools. Ironically long tested learners don't make them become skillful language users. Their sole goal in learning English is to acquire higher scores. In response to most voices against it, China is ready to implement the English gaokao reform. Hopefully English will be totally removed in 2017. As we know, the reform is not to reduce the power of the English language, but force learners to learn it and use it as a communicative tool. Standing at the top of education, college English shoulder more difficulties, and are confronted with more challenges. In this paper a frontline teacher conducts some exploratory methods in order to help college students to learn English in a practical way, hoping that more educators can rethink about it and the efficiency of EFL teaching and learning will be improved in years ahead.
\end{abstract}

Index Terms - way, college English, reform, national college entrance exam

\section{INTRODUCTION}

Since 1980s, English has been a required test for the national college entrance exam (also gaokao). Nearly all the students have to acquire high scores if they want to be accepted by top universities in China. The English test is accounted for 150 points in " $3+\mathrm{X}$ ", with Chinese and Match accounted for 150 points respectively, and " $\mathrm{X}$ " standing for politics, history and geography for arts students; and physics, chemistry and biology for science students, which each accounts for 300 points. In 2013, the Ministry of Education released a draft reform plan for gaokao, making it known to the public that English will be excluded in gaokao in the future. According to the plan, English will not be a gaokao test subject. Instead, students can take English tests more than once each year; and only the highest score will be counted in total score for college entrance exam. ${ }^{[5]}$ Before the English test is totally removed from gaokao, the English score is reduced each year, 120 points in 2015 with the reduced 30 points added to the Chinese course, 100 points in 2016, and no English test in gaokao in 2017. In an effort to lessen academic pressure and readjust once-in-a-lifetime exam system, the English tests will be held several times in a year and let students have an option to decide when and how often they will take the test. ${ }^{[2]}$

As is known to all, the English test has made most test-takers feel frustrated, even been taken as a greatest nightmare. No matter what the reform is, some basic problems should be taken into consideration. Over 30 years of the English test in gaokao, few people can use English properly in real life, even for those with high scores just have large vocabulary in mind and master grammar proficiently on paper. After the reform news, it has aroused a heated discussion among educators around China. As a college English teacher, it is not wise to take a "let-it- happen-naturally" attitude, after all two or three years later those learners will sit in class, taking the English course as nothing at all. Where is the way out for college English education? Do as most learners expect: making college English learning as English music or movie appreciation lessons? But after high education receivers' graduation from college, they have to "show" their language skills in a communicative way, instead of boasting of how many English songs or movies they have been showed. In response to the gaokao English reform, there should be one, two or more educators doing the similar work who take some initiatives no matter what the result. Started in September 2013, in order to know about college freshmen's English learning activities, a bunch of investigations were conducted: three important test scores were collected and analyzed besides constant class observations and immediate practice and correction were made.

\section{METHODOLOGY}


In September 2014, two freshman's classes were chose as the target students in the current research. There are 31 students in food and security class, and 30 in law class. Nothing was told to them in relation to the research. Everything is done as a normal English class. After being introduced of college English learning strategies at the first lesson, three questions were asked. To make the task less nervous and better understand what was in their mind, written form was required.

\section{Question 1. Why do you learn English?}

\section{Question 2. What's your most difficult part in learning English?}

\section{Question 3. How do you look at the freshmen who major in English?}

They are old questions, but different opinions are contributed by new generation of freshmen each academic year. For question 1, years ago, many freshmen answer: I have no interest in English but I have no choice as it is a required course. For these two classes of 2013, most mention that they are conscious of the importance of English, and they will continue to work hard at it though it is not easy to do so; some even stress that although they were not interested in it, for the sake of a prosperous future, they still like to try hard. For question 2, students write about that, before college they were busy with various exercises and tests either in class or out of class; they did not take time to practice their English as a communication tool. As a result, listening and speaking skills are their most difficult part. But the truth is, according to their written answers on paper, their vocabulary needs to be expanded, and grammars to be strengthened. Less than a quarter of 61 students write complete sentences with correct spellings and grammar. For questions 3, one-third of the students admire English-majors as language genius. The fact they don't know is that not every English-major is an expert at the English language. It is better for them to find it out. However at least in their deep heart, they have a positive attitude towards English learning. Another part of students would love to hear about how English-majors learn English as they are experienced learners. Still some students think it is unimaginable to spend the whole college life with English. The next time satisfaction and encouragements are expressed in class. Besides that, the fourth question is asked.

\section{Question 4. What do you think how we improve our English in class?}

For this question the suggestions are given in the order of the number of contributors: A. Let us speak more and train our listening ability; B. Watch movie or listen to music; C.A good learning environment is created and thus English should be used as a class language; D. More Chinese is used for better understanding of the usages of language points, sentence structure and other new knowledge concerned; E. Explain English knowledge in the textbook in details. Appreciative of everything they have offered, I need to rethink college English teaching: for students' successful graduation, for their prosperous employment opportunities, or for their reliance on college English teachers.

To help them, to know them first. From the admissions office, I got their English scores in the national college entrance exam (gaokao), and recalculated those using 100 points for future comparison. (See figure 1)

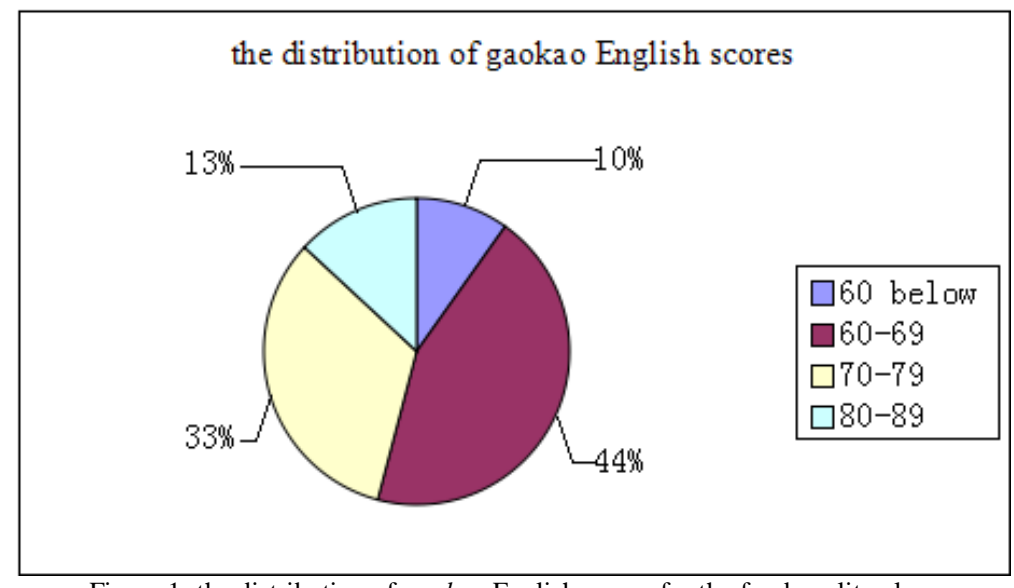

Figure 1: the distribution of gaokao English scores for the food quality class

If we have to classify the students into four levels, 60 below is graded as bad (F), 60-69 as so-so (D), 70-79 as OK (C), 80-89 as good (B). Obviously from above, most students are OK level. There is none for excellent (A).

As to the national college entrance exam in Sichuan province, there are three parts: one is the practical use of English knowledge (50 points), another is reading comprehension (50 points), and the third is writing (50 points). In Part I there are Vocabulary and Grammar (20 points) and Cloze (30 points), in Part II they are passages (5 passages, 40 points) and a cloze-test passage (10 points). And in Part III there is a short-answer passage, a proof-reading passage, and a composition. From the distribution of each part, we can tell that the stress is laid on reading and writing skills. Wherever the question of China's English education is raised, there will be a heated discussion: current testing system is a major criminal, teachers are incapable or irresponsible, Chinese students are lazy, or it is hard to find a positive language environment. As a consequence China's English learners are characteristic of "dumb English" or "deaf English". There seems no big difference in their practical skills in English between a high school graduate or a college degree beholder. Years ago when a famous linguist spoke of China's English teaching, he emphasized "low efficiency" 
(Hu, 2002). As a frontline English teacher, I have concluded the following three reasons for the current situation.

\section{A. Blame on One-size-suits-all Exam System}

Undoubtedly many people will make a long list of disadvantages for it. From one learning stage to next one, no exam can be escaped, while English plays an equally important role as Chinese and Math do. The higher (score) the better access to a more decent school (university) or find a better job. It is a must to acquire higher scores in Secondary School Entrance Exam, National College Entrance Exam, and College English Test Band 4/6 for non-English majors, and Test for English Majors Band 4/8. Since all the students attend an identical test, the miracle is created out of how hard teachers and students work in class. To help students achieve higher scores in the exam, teachers do loads of work to analyze and compare with test exercises of the previous years. No wonder similar points of knowledge is tested each year, even new points of knowledge might be predicted by some "genius" teachers. Consequently the best strategy adopted is to let students totally immersed in mountains of exercises both in class and after class. They believe more means higher possibility of "meeting" them in the exam. If some knowledge has nothing to do with the test, both teachers and students will skip it automatically. As is explained above, .there is no listening comprehension for gaokao English in Sichuan province. Thus there is not much listening practice in English class, if it is not at all, to say nothing of speaking skill practice. During the fifteen years of English teaching career, I am always told at the first lesson in each academic year "my English is very bad especially my listening and spoken skills as we don't get trained before college". Personally the exam itself cannot be blamed as in many ways it is an ideal assessment for self-check or checking our teaching and learning. The current problem is that it serves as a tool to pass all kinds of exams and learners become slaves to them instead of devoting themselves to their improvement of skills as a way of communication. ${ }^{[1]}$

\section{B. Ignorance of Different Levels of English Proficiency}

Students entering a new learning stage of meet new people with different levels of English. Some come from a prosperous city, or some from a remote village; some graduate from a famous school, or some from an ordinary school. Different backgrounds affect their English very differently. "Good" schools with new modern technologies offer students opportunities to listen or watch some English materials, or invite some English-speaking guests to give lessons or lectures, which is of great encourage for learners. Students from "bad" school are not lucky enough to get access to new learning stuffs, even some English teachers are borrowed from or shared with other schools, and they might never have a chance to "see" a foreigner at all if not leaving their town.

Take our university as an example. Located in a small city in west China, it admits college-bound students from twenty-three provinces all over the country. Initially the whole country had a uniform set of test papers with exact date of testing time for certain courses in gaokao. Starting in 1985 some provinces have their own sets of test exercises in order for a better adaption to regional difference. For instance, normally in eastern provinces they have listening comprehension in gaokao, and practice listening skill in class. However, in western areas such as Sichuan and Chongqing, they treat English listening comprehension differently. There is no listening comprehension in Sichuan, there accounts for 30 points in Chongqing: five short conversations ( 7.5 points), four dialogues (18 points), and a monologue (4.5 points). Why I emphasize listening comprehension is that this skill is a fatal weakness for college students, and listening comprehension accounts for 35 points (the total scores 100 points) in final exam and $35 \%$ (the total scores 710 points) in CET-4/6 (College English Test). When students are getting together, they will be put into a certain class by majors, and then combined with another (class) into a bigger one for English lessons (60 students more or less). Luckily English majors usually are given lessons in the form of natural class (about 30 students).

\section{Shortage of Resources for Hardware Facility and Teaching Staff}

This point was emphasized in a speech given in 2005 at Universität Klagenfurt. ${ }^{[4]}$ In this research the two classes are combined into a new class (61 students) for college English teaching. Usually in the first semester, I can give lessons in a multi-media classroom where more English materials can be shown to students with modern technologies, in the second semester (spring semester) there are so many other courses who are first choices to use multimedia classrooms, English is the last choice, and thus I teach English in an ordinary classroom with everything written on a blackboard. The usual way to train listening is through teachers' talking, and to let students speak more to practice speaking skills. In the countryside campus where I work, there are three language labs, but the facilities at least have five years long, especial under the situation of improper management. Fortunately things are quite different in main university: there are eight labs with advanced facilities and all the classrooms connected to the internet.

I graduated with B.A. Degree in English education, and two thirds of thirty classmates are English teachers in high schools. The other day I had a quick inquiry via QQ about how many classes they have in a week. Twelve classmates respond: everyone has over fourteen 45-min classes. In our English department, we have sharp difference in class arrangement. There are three campuses for our university: one in the countryside, two others in the city. Many teachers don't like to commute as they live in city. In the countryside campus, twenty-eight teachers undertake the teaching task of over 200 classes (about 7,000 freshmen). Roughly speaking each teacher has eight classes, and the truth is that few teachers have twelve 45-min classes in a week, most have sixteen 45-min classes, and some (three teachers for sure, me included) have twenty 45-min classes. I am not complaining, but making a point. The other day I read about that in China most foreign English teachers don't know how to teach, while the saddest thing is that schools hire native 
English-speaking people just to attract more students. ${ }^{[3]}$ In this sense the removal of gaokao English is a heavy slap against opportunists. Not a single article about China's English teaching mentioned that China is starving of English teachers. Wrong! In my opinion what we are in most need of is to promote teachers' teaching enthusiasm, and offer them more opportunities for personal growth.

\section{ANALYSIS AND DISCUSSION}

As everyone knows, any language learning includes listening, speaking, reading and writing. In our university non English majors are the textbooks compiled by Foreign Language Teaching and Research Press. Two textbooks are used in class: one is Reading and Writing, the other is Listening and Speaking, with both books attached to CD-ROM. In the book of Reading and Writing, there are ten units, and in each unit there are Section A and Section B. In my understanding Section A is aimed at intensive reading, which is composed of vocabulary, text and the following exercises of short-answer questions, reinforcement of new words and phrases, sentence structure (grammar revision), translation (from Chinese to English, and from English to Chinese), and structured writing. Section B is for extensive reading, which consists of vocabulary, text and the exercises related to the comprehension of the text and the reinforcement of vocabulary. The time allocation is to spend four 45-min classes (4 class periods) on Section A, two class periods on Section B and another two classes on the book of Listening and Speaking. The most common method used to be like that: learn new words by giving examples of its usage, study text by explaining the whole sentence by sentence, and do exercises by dictating or writing down the keys on the blackboard. There are not many other assessment ways except having dictations for new words.

For long-tested freshmen reading and writing continue to be their difficult parts in learning English. The very first step is to correct their pronunciation. To train their speaking skill, let them listen to CD, follow the speaker, get them to read aloud individually, have reading competition after that. Since it is a large class, divide the whole class into teams, and a different student is required to read each unit. Once they are familiar with English pronunciation, sentences should be read properly. Again listen to the passage, and pay attention to how the speaker reads each word in sentences. Now some students may question "why some words are pronounced differently from when we learn them in vocabulary part?" I respond: "Do we speak Chinese word by word?" Then I will emphasize the variations of sounds in English, and suggest listening more and reading aloud frequently and fluently as rules are complicated to explain for non English majors. In the later listening practice, I feel quite encouraged that they can figure out "a costly investment" and "She won't feel offended if a student falls asleep". Reading and speaking are closely related using the textbook of Reading and Writing. As far as my knowledge is concerned, it is not quite necessary or helpful to practice speaking skills using simple daily life situation like greetings, asking for directions or giving advice, which are over-used in textbooks before college. Text-oriented strategy is employed in class. Take the example of the text (its title is A Good Heart to Lean on) in Unit Three, Book I, it is about a crippled father who influences his son with his good qualities. For it I prepare two tasks for students: basic questions and group discussion. For one thing, questions are designed to encourage students to speak more. For another, sometimes learning something makes us think, and teaches us more than knowledge.

Question 1: According to paragraph 1, what do we know about his father? (very short, crippled)

Question 2: Explain how severely his father is crippled. (need someone for balance when walking; it is impossible to walk on snowy ground even with someone's help; cannot stand unaided on soft sand.)

Discussion Topic 1: Describe what kind of person the writer's father is. (Find out facts to show his father has a good heart.)

Discussion Topic 2: Explain the changes of the writer's feelings about his father. (embarrassed as a child; proud when growing up; guilty and grateful after he passed away.)

For question part (task 1), most students can give satisfactory answers by using the information from the text, though some read the correct sentences to the class. For those who read, I will let them recite what is read afterwards. For discussion topic 1, they don't know how to answer it; most just pick out some sentences from the text and read them as the answers. To answer it, we have to understand the examples the writer shows us, and think what he wants to say about his father related to his qualities. For discussion topic 2, it is easier for them as the writer concludes how he feels as a child and as a growing man, for the third stage (after his father passed away) they fail to find some proper words to describe the writer's feeling. Now we can draw a conclusion that most freshmen stay at the level of understanding the text literally.

Next is listening skill. Amounts of materials are added besides the textbook. Word dictation, sentence repetition and spot dictation are for the initial stage of practice. Listen at the first time, read aloud what's heard after giving the correct answers, then listen for the last time without looking at the correct answers. My rule is to test yourself for real at the first time, to correct your listening by knowing the answers, and to strengthen them for the third time. The second stage is to understand short conversations, long conversations, and passages, with the difficulty added according to their progress, starting from high school listening materials.

The last is about writing. At the freshman year, I don't give them any writing assignment. Firstly, freshmen are bits busy with other courses and extra-curricular activities. If I assign it, they will copy one from the internet, which frustrates me more. Secondly as long as a student can write complete sentences with correct grammars, that's a good base for composition. When learning new words or doing Chinese-English translation, I will let them do it in class, no 
preparation before class. To translate a sentence, there are three steps to follow: analyze the sentence structure (a simple sentence or a complex sentence); determine tenses or voices; and make sentences with familiar words, phrases and structures. When one is asked to translate, others listen attentively. If there is something wrong, I will invite another student to correct. It takes time and patience, but it is quite rewarding. In December 2013, they attended college English test band 4 (CET-4). In March 2014, I downloaded their scores from the website of our university education department. Below is a figure (see figure 2) about the percentage of scores in listening comprehension, reading comprehension and the writing part, of which the total scores are composed.

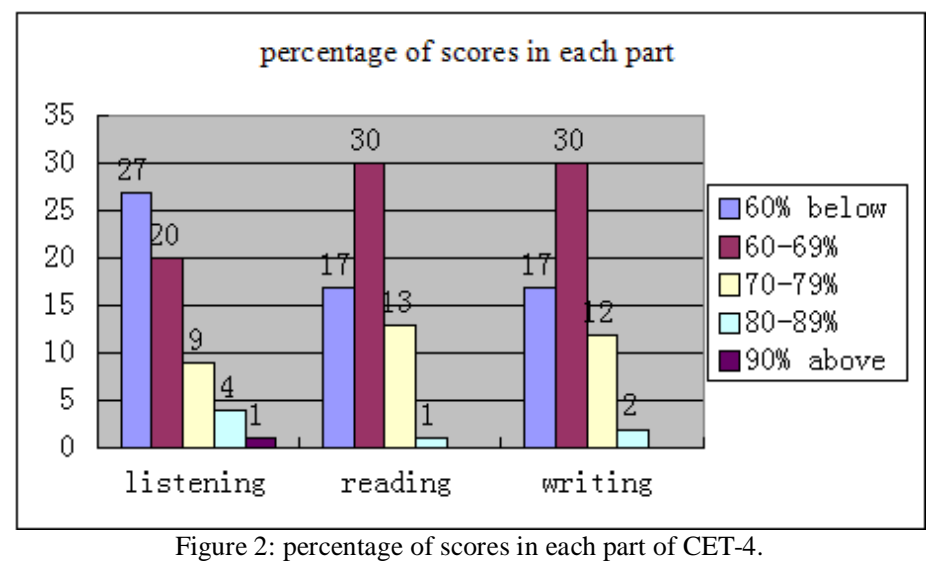

Compared with gaokao English, CET-4 test includes a bigger scope of comprehensive knowledge as a language use. Listening comprehension accounts for 35\%, reading comprehension 35\%, and the writing accounts for 30\%. The most difficult part for college students is the listening. It has three sections: Section A is eight short conversations and two long conversations; Section B is three passages, and Section C is compound dictation. From the figure above, we can see listening skills can be improved efficiently over tough training, although it has the highest percentage of losing scores. Sadly reading and writing stay at a unsatisfactory level as before college students have accumulated experiences in dealing with them. In the mid-term of the second semester (spring semester 2014), in order to improve our English class, students were asked to write anything about their English learning or teachers' teaching. Honestly before that I had thought that students would express their satisfaction with their learning and our cooperation because they did exceptionally well with CET-4 compared with former freshmen in any other grades. To my surprise, they have new expectations for their goals, except that they are working hard at CET-6 (preparing for another authorized test). Majority of students suggest they be given more opportunities to "use" English in class, and few students advise we watch more movies or listen to music in class. Instead they say that, encouraged by their performance of CET-4 over honest hard work, they would love to reinforce their practice skills both in and after class. They want to have more practice (competition) in class as a good language environment can be very encouraging. Movies and music adds extra interests to their extra-curriculum learning activity. What a relief! The existence of some "authorized" tests is necessary. The problem lies in how to handle it properly.

\section{CONCLUSION}

So far it is hard to predict to what extent this reform will benefit English learners. What is mostly acclaimed is that we are taking actions to what's regarded as something bad by most people. It is not wise to put the blame on the policymakers, or on the language teachers, or on the language learner. Every party needs to do our bits to improve ourselves in a positive way. For the policymaker, it is a need to keep a close contact with the teaching and learning group, knowing their needs, and remedying something efficiently. For the education administration of the schools, have a frequent meeting with frontline teachers, listen to them, and have a scientific time allocation for Lang classes. For teachers, think more about being patient, helpful and efficient. Lastly for language learners, stop being slaves to tests, and learn English actively as a communication tool.

\section{REFERENCES}

[1] Beckie, Smith. (2014). China: Engish Language Testing to be Removed from Gaokao. http://thepienews.com/news/china-remove-english-language-testing-gaokao/ (accessed 26/5/2014).

[2] Liping, Gu. (2014). English out of the Gaokao; What happens Next? http://www.ecns.cn/2014/05-19/114733.shtml. (accessed 26/5/2014).

[3] Shuangmiao Han. (2013). Gaokao Reform and International Higher Education. http://www.universityworldnews.com/article.php?story=2013120315410165.(accessed 26/5/2014)

[4] The Present Situation of English Education in China: How to Find a Way out of the Difficulties. A speech made in 2005 at Universität Klagenfurt. http://blog.sina.com.cn/s/blog_5f29458c0100n68c.html. (accessed 29/5/2014).

[5] Xinying, (2013). Zhao. Gaokao Reform 
http://usa.chinadaily.com.cn/china/2013-12/08/content_17160395.htm. (accessed 26/5/2014).

[6] Zhuanglin, Hu. (2002). The Issue of Low Efficiency in China's English Teaching, Foreign Language Teaching, 4, 3-7.

Liu Peng, was born in Chongqing, China in 1976. She received M.A. degree in applied linguistics from University of Electronic Science and Technology of Chengdu, China in 2012.

She is currently an English lecturer in School of Foreign Languages, Sichuan University of Science and Engineering, Zigong, China. Her research interests include EFL teaching and western culture.

Xianjun Tan, was born in Zigong, China in 1980. From Set.2007 to July 2008 he studied the Spanish language in Havana University (Havana, Cuba) in a national project "Human Resources Training of West China". In June 2009 he graduated from University of Electronic Science and Technology of China (Chengdu, China) with M.A. Degree in applied linguistics.

$\mathrm{He}$ is currently an English lecturer in School of Foreign Languages, Sichuan University of Science and Engineering, Zigong, China. His research interest includes foreign languages learning and western culture.

Fang Xie, was born in Zhongxian, China in 1978. She received M.A. degree in applied linguistics from University of Electronic Science and Technology of Chengdu, China in 2012.

She is currently an English lecturer in School of Foreign Languages, Sichuan University of Science and Engineering, Zigong, China. Her research interest includes sociolinguistics. 